\title{
Article
}

\section{Learner-Created Podcasts: Fostering Information Literacies in a Writing Course}

\author{
Stephanie Bell
}

York University

\section{Abstract}

This paper describes an experimental learner-created podcasting assignment in a first-year undergraduate research skills course for professional writers. The podcasting assignment serves as a contextualized experiential writing project that invites students to refine their research skills by participating in the invention of an emerging genre of radio storytelling. The power of the podcast assignment lies in the liminal space it creates for learners. It moves students beyond familiar and regimented essay conventions to an unstable writing environment where digital tools for producing, publishing, and negotiating meaning offer a range of possible audiences, modalities, forms, and modes of meaning making. This space creates the pedagogical conditions for epistemic development, through which students adopt as their own the research practices of adept and experienced writers. The multiple demands of this course on writing, research, and digital environments generates the beginnings of interdisciplinary writing pedagogy involving Kent's $(1993,1999)$ postprocess mindset, the ACRL's (2015) Framework for Information Literacy in Higher Education, Baxter Magolda's (1999) constructive-developmental pedagogy, and Arroyo (2013)'s elaboration of participatory digital writing pedagogy.

\section{Introduction}

In this paper, I reflect on an experimental learner-created podcasting assignment I've been developing since 2013 in a first-year undergraduate research skills course for professional writers working in digital environments. The podcasting assignment provides a contextualized experiential writing project that invites students to refine their research skills by participating in the invention of an emerging genre of radio storytelling, what Ira Glass of National Public Radio has described as "narrative journalism" or "compelling stories" or "radio that's actually good" (Abel, 2015, p. 11). The 
Volume 29, 2019

http://journals.sfu.ca/cjsdw

power of the podcast assignment lies in the liminal space it creates for learners. It moves students beyond familiar territory-the "noble" essay (Andrews, 2003, p. 117) and its regimented conventions and modes of meaning making - into an unstable writing environment where digital tools for producing, publishing, and negotiating texts offer a range of possible audiences, modalities, forms, and modes of meaning making. In this space, students are afforded resources to achieve agency because they are positioned as authors making their own design decisions in the context of a publicfacing text with a life beyond assessment.

Experimentation with learner-created podcasts is hardly new (see Guertin, 2010), and neither is the revelation that they offer resources for learner agency. Instructors tend to report productive experiences with learner-created podcasts, indicating that they can help students build and share knowledge in more creative and collaborative ways than traditional assignments permit by practicing self-conscious and reflexive learning; developing technical, research, and oral communication skills; and learning through the opportunities afforded by disseminating work beyond classroom confines, such as community and civic engagement (see Sprague \& Pixley, 2008; Armstrong, Tucker, \& Massad, 2009; Bruce \& Lin, 2009; Struck et al., 2011; Bolden, 2013). Most notably, however, Lee, McLoughlin, and Chan (2008) describe learner-created podcasting projects as a unique "modality of learning" (p. 504) that affords students unique knowledge creation and dissemination opportunities. They draw on collaborative and constructivist learning pedagogy to understand the ways learner-created podcasts foster collaborative problem solving and knowledge construction among students. In their modest study of an extra-curricular podcasting project involving focus groups with five student participants they find evidence of knowledge-building principles, including "progressive problem-solving" and "epistemic agency," where students described collaborating with each other in order to refine ideas in light of divergent opinions (p. 513). The authors reason that the learner-created podcasting project achieved a knowledge-creation discourse because:

the shared social context and focus on a common goal resulted in a highly cohesive team of student-producers, where mutual respect, open communication and the pursuit of a common goal were key factors that ensured ongoing exploratory dialogue and a commitment to sharing ideas, as well as to individual and group learning. (p. 516)

My intentions were to use a learner-created podcast project to create the pedagogical conditions for epistemic development, through which students adopt as their own the research practices of adept and experienced writers. This is because epistemic development involves movement toward 
Volume 29, 2019

http://journals.sfu.ca/cjsdw

research practices that are rooted in an understanding of writing as a knowledge-making activity and of knowledge as contingent, constructed, and social. I come to this pedagogical approach and formulate the conditions for epistemic development by virtue of Kent's $(1993,1999)$ postprocess mindset, the American College of Research Libraries' (ACRL) (2015) Framework for Information Literacy in Higher Education, Baxter Magolda's (1999) constructive-developmental pedagogy, and Arroyo's (2013) elaboration of participatory digital writing pedagogy. I have strayed from writing studies' typical focus on research as discourse practice involving strategies of source use, engagement, and attribution in relation to authorial positioning, identity, and ethos in a quest for guidance on how to foster the attitudes and dispositions that lead students to adopt as their own the research and source engagement practices of expert writers. What I begin to articulate in my response to the multiple demands of the course about writing, research, and digital environments is an interdisciplinary approach to writing pedagogy, which I put into practice in an experimental learner-created podcasting assignment.

\section{Design considerations: An interdisciplinary approach}

What research skills do professional writing students need to develop in the first year of their studies? I put this question to my colleagues at the outset of my course design efforts, and they described a variety of successful practices of upper-year students, including: moving beyond the first Google search result, persisting when information doesn't appear to be readily available, engaging with carefully selected sources, and demarcating between sources and voices. I emerged from these discussions confident that I could explain, demonstrate within specific genres, and rationalize these practices in my first-year research course, and both require them of my students as well as assess them. However, I was not confident that I could facilitate a sustained shift toward these practices through explicit instructions or traditional research-based writing assignments. The task ahead of me seemed to involve initiating a process of becoming a professional writer by shifting perceptions of what research-based writing is and does. Motivated by Kent's (2011) criticism of the notion that writing can be taught through "pedagogical injection of efficacious rules...that embody the necessary and sufficient conditions required for successful written communication" (p. xvii), I set out to devise a situated, public, and interpretive experiential writing project that would provide students with the resources to adopt effective research-based digital writing, as promised by the course's calendar description. 
Volume 29, 2019

http://journals.sfu.ca/cjsdw

I was encouraged in this tact by the librarians I consulted regarding the design of this research course, who pointed me to the shifting landscape of information literacy pedagogy away from skillsbased instruction abstracted from sites of practice. This development in information literacies theory has since been articulated in the ACRL's (2015) Framework for Information Literacy in Higher Education, which insists that librarians and disciplinary faculty must do much more than inform students of information literacy concepts and the knowledge practices that uphold them. Rather, they must provide opportunities within disciplinary contexts for students to engage with what the Framework identifies as key "threshold concepts" of information literacy: the constructed nature of authority, the process by which information is created, the value of that information, the scholarly conversation, the inquiry that drives research, and the strategic exploration that characterizes scholarly research practices. A central contention at the core of the Framework is that engagement with these core information literacy concepts corresponds with the development of: first, knowledge practices, the complex strategies faculty might describe successful upper-year students practicing such as evaluating information on the basis of multiple factors from its creation process to its impact on the developing text to its potential power with an intended audience; and second, learning dispositions, the "affective, attitudinal, or valuing dimension" (p. 8) of knowledge making, such as open mindedness, information skepticism, self-awareness, and self-reflection (pp. 12-13).

The causal connection drawn here between epistemic development through information literacy thresholds and these practices and dispositions correlates with Kent's influential work in postprocess, which turns writing pedagogy away from teaching writing as a set of practices and skills to creating opportunities to adopt effective writing practices by virtue of public, situated, interpretive writing experiences. The implications for pedagogy are significant on both accounts here, though neither Kent nor the ACRL prescribe teaching approaches. In fact, they are rather resistant to such prescription. It is possible to abstract a common value for learning through experience and writing projects that offer opportunities for students to engage in communicative acts. This approach is confirmed in the constructive-developmental pedagogical theory formulated by Baxter Magolda (1999), which identifies epistemic development as the primary aim of teaching and learning. Baxter Magolda describes epistemic maturity in much the same terms as the ACRL's revised Framework, casting it as a form of contextual knowing marked by information literate knowledge making practices. "Contextual knowers," she explains, formulate contingent understandings of issues by taking stock of available evidence and expert positions as well as their own personal beliefs, assumptions, and experiences (p. 53). These knowers have epistemic agency, what Baxter Magolda 
Volume 29, 2019

http://journals.sfu.ca/cjsdw

calls "self-authorship," involving the ability to respond to issues rationally and having taking stock of them rather than being reflexive or reactive; to take positions that are different from others, even when those individuals are in positions of greater authority; to construct knowledge; and to engage in relationships without losing their identity (p. 12). This description of epistemic maturity bears similarities to the ideal research practices of successful upper-year professional writing students that my colleagues described.

The conditions for fostering epistemic development, Baxter Magolda explains, are created by the three underlying principles of constructive-developmental pedagogy: validating students as knowers, situating learning in students' experience as it is relevant in the context of a course, and creating interdependent learning communities engaged in the mutual construction of knowledge (p. 26). This approach to teaching foregrounds a move away from teaching the mastery of codified information, processes, and skills toward collaborative learning environments that destabilize the teacher-student hierarchy and elevate the involvement of learner's interests, perspectives, and goals to result in transformations of experience/understanding. This notion of learning as personal transformation rather than the accumulation of knowledge and skill is fundamental to constructivistdevelopmental pedagogy and theories of epistemic development.

The landscape of epistemic maturity and information literacy has dramatically changed in the nearly two decades since Baxter Magolda's formulation. Arroyo's (2013) digital writing pedagogy also centres the fluidity of writing motivating Kent's postprocess mindset, a commitment to prepare self-directed knowledge makers in light of what the ACRL describes as a "rapidly changing [information] ecosystem" (p. 8), and a shift away from teaching mastery of codified information at the heart of Baxter Magolda's constructive-developmental pedagogy. Arroyo's interpretive and participatory digital pedagogy posits learning as distinct from skill demonstration, which she describes as futile given that the online world "never slows down enough for mastery" (p. 102). She contends that learning occurs through the use of writing to "[create, share, and develop] complex networks around a given concept" (p. 9), and describes student writers who transcend the boundaries of classrooms to join online communities as fellow "speaker-listeners" using language to generate (p. 44), (re)assemble, and connect ideas with others (p. 82). Today's information literate activities are digital-"electracy" - and involve the use of digital media as resources for participating in the social construction of knowledge. This pedagogy positions learners as inventors and makers who are affective and embodied, situated within community, interested in opening dialogue rather than resolving it, interpretive, and chancy (see pp. 59-61). All three, Arroyo's participatory 
Volume 29, 2019

http://journals.sfu.ca/cjsdw

composition, epistemic agency, and Baxter Magolda's "self-authorship," involve the ability to disrupt authoritative voices, structures, and traditions in order to remake and reassemble them as an inventive and experimental "speaker-listener" who is responsive to the fluidity of online cultures and platforms (p. 33).

Arroyo joins the chorus of calls for an experiential pedagogy "of learning, inventing, and knowing while doing" (p. 120). In this framework, teaching writing involves working together with students to invent (rather than reproduce) "from the side of not knowing" (p. 87). This invention is made possible, according to Arroyo, in classrooms that value chance, experimentation, and "choric" writing and teaching where participation is possible (p. 111). Her inclusion of professor Jenkins' description of participatory classrooms is clarifying; he describes them as:

spaces that are very open for individual contributions, where there is a supportive environment.... Where people learn together, create together, grow together, communicate together outside of some of the rigid formal structures that shape school in its current form. (qtd. in Arroyo, 2013, p. 9).

Through the learner-created podcast assignment, I respond to Arroyo, Baxter Magolda, the ACRL, and Kent with a fusion of writing teaching writing, research, and digital skills by practicing an interdisciplinary writing pedagogy. A learner-created podcasting project provides students with resources to engage with information literacy concepts within a situated, public-facing, and interpretive writing act bringing personal and embodied experience into connection with social issues within a local writing community and in connection with the online information network. The course's approach is experimental, with students who are actively involved in its constant development, in the online space, to echo Arroyo, where experimentation or (de)evolution never slows down enough for students or instructors to find solid ground.

\section{Project Details: Praxis}

My students agree that it is best to listen to the Featured Podcasts by From Scratch Media (fromscratchmedia.squarespace.com) to get a feel for what we, in particular, are inventing. The project creates a classroom that Ulmer would describe as "a place for invention rather than reproduction" (qtd. In Arroyo, 2013, p. 111), and demands that students work together as a collective to produce a podcast show unified by a common theme. While students produce 20-minute episodes individually or with a partner that explore the show theme from an angle of personal interest, they work as a collective to generate the show's look, feel, and research contributions. 
Volume 29, 2019

http://journals.sfu.ca/cjsdw

Following Baxter Magolda's (1999) assertion that learning is a transformation of the way students organize the world, we begin the course with students' personal understandings of research. On the first day of class, I ask students to articulate their understanding of "research" and to create a list of their expectations of what they will learn and do in the course. Each year, the list of expected tasks includes a library tour, demonstrations of online library databases, and assignments along the lines of annotated bibliographies. The students' understandings of research include searching for, gathering, evaluating, and categorizing sources of information, with particular emphasis on demarcating between scholarly and non-scholarly sources. These expectations reveal an understanding of writing as a codified set of principles, processes, and conventions. I begin transforming these expectations by asking students to move from thinking about what research is to what research does in the context of written communication. As we begin to consider how research practices change depending on the writer's purposes, I introduce the podcasting project-an exercise of public, situated, interpretive, and tooled writing in the context in which we will practice defining research questions; searching for, accessing, and evaluating information; and working with it to produce new understandings. Students are at once relieved that the course will not be a dry rehearsal of research skills and intimidated by the size and scope of the challenge it presents.

Students find that they are participants in a communal process of constructing the podcast show's sound, feel and goals. The absence of formalized conventions for the podcast genre they are inventing invites them to consider that writing conventions are not discrete rules that exist for writing instructors to lay bare and student writers to master. Students cannot defer to the teaching team because there simply is no answer key. Rather, they must engage meaningfully in the process of mutual enquiry to do formative genre work, explicitly playing Kent's (1999) hermeneutic guessing game at every decision point. The class works through this interpretive process together in lectures and tutorials, and through formative assessment tasks. In a few iterations of the course, we have used lecture as a large-group meeting to collaboratively author a show manual of style (used, in part, as a grading rubric for the final piece). This manual of style is the product of debate and discussion about the tone, style, and format of the podcast show as well as topic scope, information-gathering strategies, types of resources, principles on which to evaluate information sources, principles of interview design, as well as ethical considerations for gathering, accessing, and using information from primary and secondary sources. These discussions draw on course materials, including the textbook (Abel, 2015), instructional (how-to podcast) podcasts, sample podcasts, research guides, and relevant ethical guidelines around copyright, academic integrity, and journalistic ethics. 
Volume 29, 2019

http://journals.sfu.ca/cjsdw

We use small-group gatherings in lecture to workshop individual progress and bring student experience to the centre of the curriculum. Students help each other brainstorm research directions, work together to create narratives from sprawling notes, situate themselves in the story to create intimacy with listeners, read sections to each other for listener feedback, use sticky notes to storyboard episode structure, determine research gaps and required fact checking. A number of formative assessment pieces scaffold this progress. These pieces have varied across course offerings, but have included a genre analysis assignment, episode pitch, research plan, episode outline and annotated bibliography, blog-style reflections, episode snippets, draft transcript, peer fact checking, and substantive editing.

The challenge of inventing a text is pressurized by the public nature of the students' efforts. Not only are their behind-the-scenes efforts, the subject of lecture and tutorials, but also the product of their efforts, their podcast episode is published to the From Scratch Media course website where it is available in audio and as a written transcript for public consumption. In addition, a selection of episodes are chosen by the teaching team to be featured (with the students' permission) on the course website home page, on its iTunes feed, and social media accounts. Initially, students experience trepidation about this, which is understandable given that school writing is typically framed as a private act, a medium for evaluation of one's mastery in a course. To ease some of this anxiety, I permit students to publish under a pseudonym and assure them that they may request to have their work taken down from the site at any time after their completion of the course. Few students end up actually taking advantage of these measures; most students are surprised and proud of their work and are willing to share it online.

The public nature of the project provides a real audience that supports the situated and interpretive nature of the task. Students get to imagine the kind of uptake they want and from whom. For example, in the fall 2016 course offering, students produced the podcast show A Place for Passion, which explored charitable, social justice, or educational projects, the individuals whose passion drives them, and their scholarly, statistical, or social rationales. In class, we discussed and experimented with methods of being critical of our research subject's (often our interviewee) work. Discussions of this sort are not necessarily scheduled, but tend to arise organically as students anticipate potential responses to their episodes. Common discussions that students initiate as they work through the project involve matters of intellectual property, source attribution in an audio context, and their power to elevate some voices and perspectives over others. These show meaningful engagement with core information literacy concepts and opportunities for 
Volume 29, 2019

http://journals.sfu.ca/cjsdw

transformations of experience as students internalize professional standards and codes of conduct that seek to regulate the responsible and ethical construction of knowledge. Another benefit of public-facing writing projects such as this is that instructors are able to provide feedback (and evaluations) based on this context, offering their own best guesses about what may or may not be effective, rather than appealing to personal authority or codified principles of good and bad writing.

Our student podcasts have started to see some uptake, both positive and negative. After A Place for Passion was published in 2016, one interviewee reached out because she felt unfairly and inaccurately portrayed in the episode. In consultation with the student, we decided to take down the episode from the site. In two other instances of uptake, we received requests for episodes to be embedded on the websites of the passion projects they featured. The winter 2018 and 2019 show theme, A Matter of Opinion, has even more potential to garner engagement. In this show, we explore perspective, opinion, and truth by responding to a published opinion piece in a local or national news publication with audio kaleidoscopes of a sort. Episodes reveal alternative perspectives (personal, statistical, cultural, historical, sociological, psychological, scientific, etc.) on the issue at the heart of the column. We give the microphone to noteworthy perspectives ignored by the original opinion piece in an effort to "empower listeners in a world of fake news." Students are encouraged to tweet links to their episodes at the news outlet(s) and columnist(s) to whom they are responding.

The choice of an audio genre is purposeful, even though it presents an additional challenge to students unfamiliar with the technology. Helping students to recognize their role as knowledge makers with (or without) power can happen through disruption that prompts them to carefully consider their authorial voice and identity. In the podcast, this disruption often seems to occur around discomfort with the sound of our recorded voice. This discomfort is natural; our recorded voice is uncanny, at once familiar and foreign. We are used to hearing our voice filtered through the internal resonance of our head. Hearing our recorded voice is a bit like looking in a mirror for the first time; is that how other people hear me? The unsettling experience of hearing yourself speak from outside yourself, and it has the power to call attention to embodied writing: persona, identity, purpose, and impact. Questions around style-How am I speaking? —lead to questions of contentWhy am I speaking? —and questions of impact-To and about whom am I speaking, and what will they think of me and my words? In this way, the experience calls upon students to write within and through digital writing tools as they extend "the boundaries of our consciousness" (Brooke \& Rickert, 2011, p. 169) to enable and constrain the ways we make meaning and the meaning we make. 
Volume 29, 2019

http://journals.sfu.ca/cjsdw

The tooled-up nature of the digital writing project offers a unique opportunity for students to consider their voice as knowledge makers as well as to the role communication tools have in knowledge making. In class, questions about when in the process to record the episode prompts discussions that reflect on the electrate information landscape, in which our recording software (not to mention search engines, information databases, social media networks) form a complex of media that serve as "apparatus, or social machine, partly technological, partly institutional" (Ulmer qtd. in Arroyo, 2013, p. 2). We consider the extent to which software serves as an audio container into which episodes can be deposited and as an additional appendage, an extension of our consciousness that shapes our thinking by "changing our ways of being in the world" (Brooke \& Rickert, 2011, p. 170). Many students choose to record the episode pitch and periodic episode snippets so they can use them as formal opportunities to listen as they write and invent with an ear towards the aural/oral rhetorical situation. Through this process, students craft narrative focus and structure organically rather than from predetermined prescriptions of form.

\section{Reflections on Praxis}

What stands out from practicing this interdisciplinary writing pedagogy is the experience of decentering the certainty and comfort created in classrooms that foreground concrete skills and that frame writing as a product that can be produced through adherence to a prescribed process and genre conventions. This decentering is also caused by public-facing, embodied/voiced, and inventive aspects of the project, which prompt vulnerable experience of self-awareness. I have observed this affective experience of the course anecdotally, in the student reflections I assign and tutorial discussion, as well as in a formal (REB-approved) survey of all students who took the course between 2014 and 2016. These data show that many students to report increased levels of stress and anxiety compared to more traditional writing projects (essays, research papers) throughout the project as a result of having been unmoored from the comfort of known conventions and expectations.

This anxiety seems to correlate with feelings of resentment and resistance as well as pride and accomplishment. Baxter Magolda (1999) explains that "when many of us genuinely try to engage students differently, we become the source of their dissatisfaction" (p. 5). Reports of student resistance and negativity about learner-created podcast assignments are not unheard of in the literature despite publication bias towards descriptions of successful pedagogical approaches (e.g., Struck et al., 2011). Baxter Magolda (1999) finds solace in Parker Palmer's note that that "dissatisfaction may be a sign that real education has happened" (p. 5). Indeed, student reflections on 
Volume 29, 2019

http://journals.sfu.ca/cjsdw

the course in the final blog entry consistently counters this experience of anxiety and resistance during the process. These blog entries include reports of feeling pleasantly surprised and proud of what has been produced, despite or as a result of the experimental project that tasked them with leaving their comfort zone. Students describe their published work as "pretty cool" and even "semiprofessional." For instance, one student writes "Never in a million years did I imagine myself doing something like this," and another student encourages others "to fully engage in every step of the podcast-making process, because the experience and satisfaction you gain are invaluable." Interestingly, some students reflect on how their typical ways of "doing school" do not work in the course. One student advises her peers not to "look at the class like a class" and another describes the course as an "excellent life experience." One of the most dramatic descriptions of the experience, from students who also describe the course as "fun" and immersive, speaks to the transformative potential of the project:

Our podcast process was much like a journey, like The Lord of the Rings, in that we began bothered and bewildered, visited dark and rank places to perform our research, and resurfaced with a large and evil burden lifted from us and most of our friends long gone.

Moving forward with the course will involve ways of mitigating the experience of anxiety, resentment, and resistance without losing the productive experience of decentering. In my most recent course offerings, I have been more explicit with students about the project of "writing from the side of not knowing" and how it may make them feel. I follow Arroyo's (2013) lead and include the following quote to my course syllabus: "The students are helping to invent the future of writing" (Ulmer qtd. in Arroyo, 2013, p. 111). I have also taken steps to make the project more accessible. I now address the anxiety students experience about their recorded voice explicitly in the course by sharing psychological research that seeks to understand the unsettling experience of hearing and seeing recordings or images of ourselves, as well as by sharing resources and exercises for creating an authentic radio persona, and by working to develop an appreciation for vocal diversity that our multivocal podcast show embraces (though we also discuss our inability to control prejudiced responses of a public audience and the option to publish under a pseudonym as a protective mechanism).

If writing is social, it is the writing instructor's responsibility to create the conditions for students to write in the world, where their words are available for others to take up. The learner-created podcast assignment transcends the classroom's walls by using online tools for self-publishing and embracing the do-it-yourself culture of maker spaces (see Bell, 2017). I have discovered that when 
Volume 29, 2019

http://journals.sfu.ca/cjsdw

student writing is public, interpretive, situated, and tooled, writing instructors do not have to tell students that they should care about writing well or writing responsibly. Rather, they must keep pace with student requests for support doing so. Writing pedagogy around research-based writing will benefit from a more sustained consideration of the interdisciplinary pedagogy I've begun to find productive. Additionally, further research on learner-created podcast projects and digital composition pedagogy would do well to investigate the ways digital media function as "modalities of learning" (Lee, McLoughlin, \& Chan, 2008) through choric invention, as students learn by writing within media that simultaneously constitute technologies and places of collaboration, composition, production, broadcast, and interaction. It appears that possibilities for learner-created digital content afford students empowered identities, from creator to author and publisher, and opportunities to build epistemic agency through composition that is inventive and social. Future research should not, however, ignore the limitations and risks involved in tasking students with unfamiliar and techenhanced projects that defy the security of textbook-guided learning and potentially expose students to the darker elements of online communities.

\section{References}

Abel, J. (2015) Out on the Wire: The storytelling secrets of the new masters of radio. New York: Broadway Books.

Armstrong, G.R., Tucker, J.M. and Massad, V.J. (2009). Achieving learning goals with student-created podcasts. Decision Sciences Journal of Innovative Education, 7, 149-154.

Arroyo, S. J. (2013) Participatory composition: Video culture, writing, and electracy. Carbondale, IL: Southern Illinois University Press.

Association of College \& Research Libraries. (2015). Framework for information literacy for higher education. American Library Association. Retrieved on 12 December 2017 from http://www.ala.org/acrl/sites/ala.org.acrl/files/content/issues/infolit/framework1.pdf

Baxter Magolda, M. (1999). Creating contexts for learning and self-authorship: Constructivedevelopmental pedagogy. Nashville, TN: Vanderbilt University Press.

Bell, S. (2017). High impact creative pedagogy using a maker model of composition. Journal of Faculty Development, 31(1), 19-24.

Bolden, B. (2013). Learner-created podcasts: Students' stories with music. Music Educators Journal, $100,75-80$. 
Volume 29, 2019

http://journals.sfu.ca/cjsdw

Brooke, C. and Rickert, T. (2011) Being delicious: Materialities of research in a web 2.0 application. In S. I. Dobrin, J. Rice, M. Vastola (eds.) Beyond Postprocess (163-179). Logan, UT: Utah State University Press.

Bruce, B. and Lin, C-C. (2009). Voices of youth: Podcasting as a means for inquiry-based community engagement. E-Learning, 6, 230-241.

Guertin, L.A. (2010). Creating and using podcasts across the disciplines. Currents in Teaching and Learning, 2, 4-12.

Kent, T. (1993). Paralogic rhetoric: A theory of communicative interaction. Bucknell University Press.

Kent, T. (1999). Introduction. In T. Kent (Ed.), Post-process theory: Beyond the writing-process paradigm (1-6). Carbondale, IL: Southern Illinois University Press

Lee, M.J.W., McLoughlin, C., and Chan A. (2008). Talk the talk: Learner-generated podcasts as catalysts for knowledge creation. British Journal of Educational Technology, 39, 501-521.

Sprague, D. and Pixley, C. (2008). Podcasts in education: Let their voices be heard. Computers in the Schools, 25, 226-234.

Struck, R., et al. (2011). Podcasts as learner-created content in higher education. International Journal of Online Pedagogy and Course Design, 1, 20-30. 